\title{
Neurological Disturbances and Self-extraction Behavior: A Review
}

\author{
Nandhini $\mathrm{S}^{1}$, Kripa Angeline ${ }^{2}$, Renuka $\mathrm{K}^{3}$
}

\begin{abstract}
Neurological disturbance describes the sudden onset of aggressive and violent behavior and autonomic dysfunction, typically in the setting of acute on chronic drug abuse or serious mental illness. It is mainly associated with delirium, dementia, and other behavioral disorders which are also collectively known as acute behavioral disturbances (ABD). Self-extraction behavior is common among patients admitted with neurological disturbances associated with certain medical and surgical disorders. The clinical characteristics of self-extraction behavior are pulling out of tubes, IV lines, interrupting medical treatment, and interfering with nursing procedures. Research literature was reviewed with regard to self-extraction behavior and its associated factors. A literature search was conducted with the following search terms, keywords, and phrases: self-extraction behavior and neurological disturbances. Totally 25 articles were reviewed by using the databases such as PubMed and Google Scholar, based on the criteria of clinical variables, demographic variables and self-extraction behavior. A considerable debate exists regarding the influencing factors for self-extraction behavior in patients with neurological disturbances. From this review, we infer that there are various contributing factors which influence the increased prevalence of self-extraction behavior among patients with neurological disturbances. The identified contributing factors are associated with clinical variables of patients. Research literature supports the necessity for understanding the associated risk factors for self-extraction behavior.

Keywords: Agitation, Neurological disturbances, Self-extraction behavior.

Pondicherry Journal of Nursing (2019): 10.5005/jp-journals-10084-12125
\end{abstract}

\section{INTRODUCTION}

Neurological disturbance describes the sudden onset of aggressive and violent behavior and autonomic dysfunction, typically in the setting of acute on chronic drug abuse or serious mental illness. It is mainly associated with delirium, dementia, and other behavioral disorders which is also collectively known as acute behavioural disturbances (ABD). ${ }^{1}$

Self-extraction behavior is defined historically as destructive actions directed toward persons, objects, or self is most commonly directed toward caregivers. ${ }^{2}$

A literature search was conducted with the following search terms, keywords, and phrases: self-extraction behavior and neurological disturbances. The search was performed in the following databases: PubMed and Google Scholar.

\section{Objectives}

A systematic review was conducted focusing on self-extraction behavior among patients with neurological disturbances.

\section{Materials and Methods}

A systematic review was conducted among 25 studies, out of which 15 were thoroughly reviewed. We primarily analyzed articles from 2010 to 2016 but included articles 2009 to 2019 due to high citation index. We examined titles and abstract to relevant reports.

\section{Overview}

Self-extraction behavior is defined historically as destructive actions directed toward persons, objects, or self is most commonly directed toward caregivers.
${ }^{1-3}$ Department of Medical Surgical Nursing, Kasturba Gandhi Nursing College, Sri Balaji Vidyapeeth Deemed University, Puducherry, India

Corresponding Author: Kripa Angeline, Department of Medical Surgical Nursing, Kasturba Gandhi Nursing College, Sri Balaji Vidyapeeth Deemed University, Puducherry, India, Phone: +91 9715262821, e-mail: angelinekripa@gmail.com

How to cite this article: Nandhini S, Angeline K, Renuka K. Neurological Disturbances and Self-extraction Behavior: A Review. Pon J Nurs 2019;12(3):76-77.

Source of support: Nil

Conflict of interest: None

\section{Characteristics of Self-extraction Behavior ${ }^{3}$}

- Self-injury,

- Pulling out of IV lines and catheters,

- Dislodging tubes and drains,

- Attempting to remove a dressing,

- Grasping cables of monitor such as pulse oximeter probes,

- Disrupting medical equipment-pulling and hitting electrocardiography (ECG) leads and monitor,

- Interrupting with nursing care procedures,

- Hitting infusion pumps and IV stands, risk for self-fall.

\section{Factors Influencing Self-extraction Behavior}

Self-extraction behavior is the common problem that occurs more frequently in patients with certain conditions, such as chronic obstructive pulmonary disease, acute respiratory distress syndrome, or cardiac disease. ${ }^{4-6}$ This increased frequency could, however, simply reflect the longer intubation periods and weaning

() The Author(s). 2019 Open Access This article is distributed under the terms of the Creative Commons Attribution 4.0 International License (https://creativecommons. org/licenses/by-nc/4.0/), which permits unrestricted use, distribution, and non-commercial reproduction in any medium, provided you give appropriate credit to the original author(s) and the source, provide a link to the Creative Commons license, and indicate if changes were made. The Creative Commons Public Domain Dedication waiver (http://creativecommons.org/publicdomain/zero/1.0/) applies to the data made available in this article, unless otherwise stated. 
in these patient groups. Some other related factors, including prolonged immobility, the inability to communicate, and nursing and respiratory procedures, increase the rate of self-extraction by $26 \%{ }^{7}$ For instance, age and duration of hospital stay have an important role in self-extraction behavior. There is a strong correlation between self-extraction behavior and duration of hospital stay.

The review commences with an overview of self-extraction behavior, and the characteristics used to define self-extraction behavior are reviewed. The review subsequently focuses on the selfextraction behavior associating risk factors in the general patients admitted with neurological disturbances. Various contributing factors associated with self-extraction behavior are reviewed and presented.

\section{Clinical Variables Associated with Self-extraction Behavior ${ }^{8-10}$}

The association between self-extraction behavior and various clinical variables has been reviewed. Variables like glasgow coma scale (GCS), serum electrolyte level, blood glucose level, acidbase levels, and blood urea nitrogen (BUN) were reviewed here. According to the review, the patient's level of consciousness is a strong predictor for self-extraction behavior, and incidence is higher in patients with a GCS score of 9-12 points. Abnormal BUN and abnormal $(<20,>50 \mathrm{~mm} \mathrm{Hg}) \mathrm{PaCO}_{2}$ were highly significant factors for self-extraction behavior. Some studies proved that the patients with electrolyte imbalances particularly hypernatremia, hypomagnesemia exhibiting symptoms like confusion and disorientation. Several studies revealed that the acid-base imbalances especially metabolic acidosis had an association with symptoms of neurological disturbances.

\begin{tabular}{ll}
\hline Clinical variables & Defining level \\
\hline $\mathrm{GCS}$ & $9-12$ \\
$\mathrm{BUN}$ & Greater than $20 \mathrm{mg} / \mathrm{dL}$ \\
$\mathrm{pH}$ & $<7$ \\
$\mathrm{HCO}_{3}$ & $>45 \mathrm{mEq} / \mathrm{L}$ \\
Blood sugar level & $>400 \mathrm{mg} / \mathrm{dL}$ \\
\hline
\end{tabular}

\section{SUMMARY}

From this review, it is apparent that studies on the international front are many, but there are relatively less Indian studies on the self-extraction behavior among patients with neurological disturbances and associating risk factors. This review clearly depicts the associated factors of self-extraction behavior. This review also emphasizes the association of clinical variable and the risk of developing self-extraction behavior. Based on this review, no clear pattern emerges with regard to the association between unhealthy practice variables and self-extraction behavior. This review highlights the fact that patients who are diagnosed with diabetes ketoacidosis, acid-base imbalances, electrolyte imbalances, and GCS are closely associated with self-extraction behavior.

\section{References}

1. Siddiqi $\mathrm{N}$, House AO, Holmes JD. Occurrence and outcome of delirium in medical in-patients: a systematic literature review. Age Ageing 2006;35(4):350-364. DOI: 10.1093/ageing/afl005.

2. Selvan K, Edriss H, Sigler M, Tseng J. Self-extubation in ICU patients. The Southwest Respiratory and Critical Care Chronicles 2014;2(8): 31-34. DOI: 10.12746/swrccc.v2i8.169.

3. Chang LY, Wang KW, Chao YF. Influence of physical restraint on unplanned extubation of adult intensive care patients: a casecontrol study. Am J Crit Care 2008;17(5):408-415. DOI: 10.4037/ ajcc2008.17.5.408.

4. Tseng J, Sigler M, Edriss H, Turner A, Valdez K, Selvan K, et al. A selfextubation case series in an ICU after the introduction of an early mobilization project. The Southwest Respiratory and Critical Care Chronicles 2014;2(8):17-20. DOI: 10.12746/swrccc.v2i8.170.

5. Chao CM, Lai CC, Chan KS, Cheng KC, Ho CH, Chen CM, et al. Multidisciplinary interventions and continuous quality improvement to reduce unplanned extubation in adult intensive care units: a 15-year experience. Medicine 2017;96(27):e6877. DOI: 10.1097/ MD.0000000000006877.

6. Suliman M. Prevalence of physical restraint among ventilated intensive care unit patients. J Clin Nurs 2018;27(19-20):3490-3496. DOI: 10.1111/jocn.14588.

7. Ertuğrul B, Özden D. The effect of physical restraint on neurovascular complications in intensive care units. Aust Crit Care 2020;66(Suppl 2): 110. DOI: 10.1016/j.aucc.2019.03.002.

8. Liu E, Murgatroyd M, Smith P. PTU-120 An audit of the use of hand control mittens with nasogastric tubes at Royal Albert Edward infirmary. Gut 2017; 66(Suppl 2):110. DOI: 10.1136/gutjnl-2017314472.215.

9. Epstein SK, Nevins ML, Chung J. Effect of unplanned extubation on outcome of mechanical ventilation. Am J Respir Crit Care Med 2000;161(6):1912-1916. DOI: 10.1164/ajrccm.161.6.9908068.

10. Kapadia F, Epstein S. Effect of unplanned extubation on outcome of mechanical ventilation. Am J Respir Crit Care Med 2001;163(7): 1755-1756. DOI: 10.1164/ajrccm.163.7.16372b. 